\title{
The outcomes of oral health promoting elderly clubs in Thailand
}

\section{Wararat Jaichuen, DDS, MPH ${ }^{1^{*}}$, Warangkana Vejvithee, DDS, MSc ${ }^{2}$}

${ }^{1}$ Health Administration Division, Office of the Permanent Secretary, Ministry of Public Health, Tiwanon Rd., Talat Khwan, Muang Nonthaburi, Nonthaburi 11000 Thailand.

${ }^{2}$ Bureau of Dental Health, Department of Health, Ministry of Public Health, Tiwanon Rd., Talat Khwan, Muang Nonthaburi, Nonthaburi 11000 Thailand.

* Corresponding Author: Wararat Jaichuen, DDS, MPH, Health Administration Division, Office of the Permanent Secretary, Ministry of Public Health, Tiwanon Rd., Talat Khwan, Muang Nonthaburi, Nonthaburi 11000 Thailand.

Received date: 24 November 2021; Accepted date: 14 December 2021; Published date: 20 December 2021

Citation: Jaichuen W, Vejvithee W (2021) The outcomes of oral health promoting elderly clubs in Thailand. J Comm Med and Pub Health Rep 2(12): https://doi.org/10.38207/JCMPHR/2021/0212257

Copyright: (C) 2021 Wararat Jaichuen, DDS, MPH. This is an open-access article distributed under the terms of the Creative Commons Attribution License, which permits unrestricted use, distribution, and reproduction in any medium, provided the original author and source are credited.

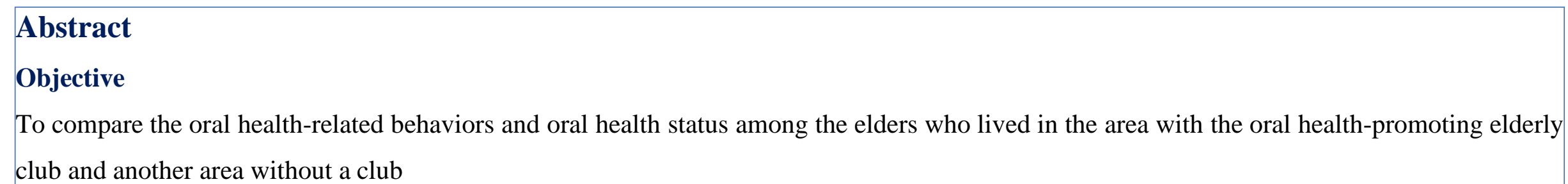

\section{Methods}

Samples from areas with and without oral health-promoting elderly clubs were compared. A structural questionnaire was used to collect demographic characteristics, oral health-related behaviors, and oral health outcomes. Descriptive statistics and the chi-square test were utilized. Results

695 from 700 respondents' data were completed. Six oral health-related behaviors, which are brushing teeth after lunch, brushing teeth at night, using dental floss, using proxabrush, never smoking or quitting smoking, and consulting dental personnel when having oral health symptoms, presented a significantly higher proportion among the group from areas with oral health-promoting elderly clubs. Having at least four pairs of occlusal teeth was the only outcome that was significantly different between the groups.

\section{Conclusions}

Oral health-promoting elderly clubs were associated with six behaviors and outcomes. By the way, smoking behavior needs more addressed. The oral health-related quality of life should be included as an indicator of oral health systems. And the new approach is needed for promoting oral health among Thai elderly men.

Keywords: elder, elderly club, oral health promotion, oral health-related behavior, oral health-related quality of life, oral health outcome

\section{Introduction}

Health promotion has been the key objective of health system reform since the campaign "Health for all" was announced [18]. The central government of Thailand also adopted health promotion as the main strategy of health system development [11]. All health-related subsystems, including oral health, followed this directive.

Oral health status among Thais has steadily improved [3], however aging society is the big issue of the country at present. The National Oral Health Plan for Senior Citizens was launched for coping with this challenge which is composed of two main strategies: promotion of oral health self-care and improving the oral health of the elderly

[2]. For implementing those strategies, the elderly clubs have been used as target settings, and become known as "Oral health-promoting elderly clubs" since 2006. The number of the clubs has gradually expanded from seven in the first year to more than 8,000 that now cater for around two million Thai elders [4]. Various oral health promotion activities are run by the clubs independently without central guidelines. The only key message relayed to oral health practitioners concerned the ultimate goal of the plan as maintaining twenty teeth and four pairs of occlusal teeth [2]. However, the effectiveness of these clubs has never been quantified and evaluated. Therefore, this study aimed to explore the outcomes of the oral healthpromoting elderly clubs in Thailand by comparing the oral healthrelated behaviors and oral health status among the elders who lived in the area with the club and another area without the club. 


\section{Methods}

This cross-sectional study used a mixed methodology. Twelve provinces from four regions of Thailand were selected as study settings. Inclusion criteria included provinces having at least one area with the oral health-promoting elderly club and another area without a club.

Participants were randomly selected from elders in the study settings. Inclusion criteria were independent elders who had lived in the study setting for at least five years and were willing to participate but excluded those who needed a translator for communication. The sample size was 350 per group, and a total of 700 elders participated in this study.

A structured questionnaire was used for collecting data. The interviewers were trained in a one-day workshop by the researcher. The questionnaire consisted of three parts as 1) General characteristics, 2) Oral health-related behaviors, and 3) Oral health outcomes. Questions on oral health-related behaviors were adapted from four functions of self-care described by Barofsky. These

\section{Results}

Data were collected from all 700 participants, but five questionnaires were incomplete. This left 695 for analysis $(99.3 \%)$. Completed data gave 617 participants who had at least one tooth remaining in their mouths, while 150 wore dentures of both included regulatory self-care to regulate bodily processes, preventive self-care to prevent disease, reactive self-care to alleviate symptoms that have not yet been identified, and restorative self-care as a prescribed treatment regimen [1]. Questions on oral health outcomes directly assessed the ultimate goal of the national oral health plan in terms of the total number of remaining teeth and pairs of occlusal teeth. The outcome of oral health-related quality of life was assessed by the Thai version of the Oral Health Impact Profile (Thai-OHIP) [11]. Data collection was conducted between July and September 2019. Descriptive statistics and the chi-square test were used to compare outcomes between elders from areas with and without oral health-promoting elderly clubs.

Ethical approval was obtained from the ethical committee on human rights related to research involving human subjects at the Department of Health, Ministry of Public Health, Thailand. Approval was given to undertake the research, and written informed consent was obtained from all participants.

professional and non-professional types. General characteristics of the elders were similar between settings. Education was the only different characteristic between the groups, participants in an area with the club had ahigher educational level (Table 1).

Table 1: Demographic characteristics of the participants

\begin{tabular}{|c|c|c|c|}
\hline \multicolumn{4}{|l|}{ Percentage of elderly people } \\
\hline Demographic characteristic & \begin{tabular}{|l} 
with an oral \\
health \\
promoting \\
elderly club
\end{tabular} & $\begin{array}{l}\text { without an oral } \\
\text { health } \\
\text { promoting } \\
\text { elderly club }\end{array}$ & $\begin{array}{l}\text { Total } \\
(\mathbf{n}=695)\end{array}$ \\
\hline \multicolumn{4}{|l|}{$\overline{\text { Sex }}$} \\
\hline Male & 31.4 & 35.9 & 33.7 \\
\hline Female & 68.6 & 64.1 & 66.3 \\
\hline \multicolumn{4}{|l|}{ Age group } \\
\hline $60-64$ years & 28.0 & 30.7 & 29.4 \\
\hline 65-69 years & 33.4 & 25.3 & 29.4 \\
\hline 70-74 years & 19.9 & 22.7 & 21.3 \\
\hline 75-79 years & 12.1 & 15.2 & 13.7 \\
\hline $80+$ years & 6.6 & 6.0 & 6.3 \\
\hline Education & $* *$ & & \\
\hline Lower than primary school & 7.2 & 13.5 & 10.4 \\
\hline Primary school & 69.7 & 69.8 & 69.8 \\
\hline Secondary school/vocational certificate & 17.3 & 10.6 & 14.0 \\
\hline Higher than secondary school/vocational certificate & 5.8 & 6.0 & 5.9 \\
\hline \multicolumn{4}{|l|}{ Marital status } \\
\hline Couple & 68.0 & 67.2 & 67.6 \\
\hline Single & 6.3 & 5.5 & 5.9 \\
\hline Divorced/Widowed/Separated & 25.7 & 27.3 & 26.5 \\
\hline
\end{tabular}




$\begin{array}{llll}\text { Normal } & 49.0 & 44.0 & 46.5 \\ \text { Having at least one medical problem } & 51.0 & 56.0 & 53.5 \\ \text { Income } & & & \\ \text { Have sufficient income } & 67.7 & 61.8 & 64.7 \\ \text { Do not have enough income } & 32.3 & 38.2 & 35.3 \\ \text { Health insurance } & & & \\ \text { Universal Coverage Scheme (UCS) } & 80.1 & 83.0 & 81.6 \\ \text { Civil Servant Medical Benefit Scheme (CSMBS) } & 19.0 & 15.2 & 17.1 \\ \text { Other } & 0.9 & 1.7 & 1.3 \\ { }^{* *} \text { P }<0.01: \text { chi-square test } & & & \end{array}$

Six oral health-related behaviors were found to be significantly different between the two groups. These included brushing teeth after lunch, brushing teeth at night, using dental floss, using a proxabrush, never smoking or quitting smoking, and consulting dental personnel when having oral health symptoms. All these behaviors were found at higher proportions in the group with access to the oral health-promoting elderly club. Three of these six behaviors as brushing teeth after lunch, using dental floss, and using a proxabrush were recorded in a small proportion of participants

(Table 2).

Table 2: Oral health-related behaviors of elderly people with and without oral health promoting elderly clubs

\begin{tabular}{|c|c|c|c|}
\hline \multicolumn{4}{|l|}{ Percentage of elderly people } \\
\hline \multirow{2}{*}{ Oral health-related behavior } & \multirow{2}{*}{\multicolumn{2}{|c|}{$\begin{array}{l}\text { with an oral } \\
\text { health promoting } \\
\text { elderly club }\end{array}$}} & \multirow{2}{*}{$\begin{array}{l}\text { without an oral } \\
\text { health promoting } \\
\text { elderly club }\end{array}$} \\
\hline & & & \\
\hline \multicolumn{4}{|l|}{ Regulatory self-care } \\
\hline Usually brush teeth in the morning ${ }^{\mathrm{a}}$ & 95.1 & & 95.8 \\
\hline Usually brush teeth after lunch ${ }^{\mathrm{a}}$ & 18.0 & $*$ & 10.9 \\
\hline Usually brush teeth at night ${ }^{\mathrm{a}}$ & 83.7 & $*$ & 75.2 \\
\hline Usually eat nothing after brushing teeth at night ${ }^{\mathrm{a}}$ & 81.0 & & 85.2 \\
\hline \multicolumn{4}{|l|}{ If wearing dentures, usually remove and clean them after } \\
\hline eating ${ }^{\mathrm{b}}$ & 78.8 & & 80.0 \\
\hline Sometimes use dental floss ${ }^{\mathrm{a}}$ & 16. & $*$ & 10.6 \\
\hline Sometimes use a proxabrush ${ }^{\mathrm{a}}$ & 26.5 & $* * *$ & 14.1 \\
\hline Sometimes use a toothpick ${ }^{\mathrm{a}}$ & 63.7 & & 66.9 \\
\hline Sometimes use mouth rinse ${ }^{\mathrm{c}}$ & 32.6 & & 39.4 \\
\hline \multicolumn{4}{|l|}{ Preventive self-care } \\
\hline Sometimes perform oral health self-examination ${ }^{c}$ & 71.2 & & 64.4 \\
\hline Never smoked/quit smoking ${ }^{\mathrm{c}}$ & 91.1 & $*$ & 85.1 \\
\hline Never chewed/quit chewing betel nuts ${ }^{c}$ & 85.6 & & 87.9 \\
\hline Rarely eat sugary snacks and drinks ${ }^{\mathrm{c}}$ & 23.9 & & 21.8 \\
\hline \multicolumn{4}{|l|}{ Reactive self-care } \\
\hline \multicolumn{4}{|l|}{ Usually use on the counter drugs to relieve oral health } \\
\hline symptoms ${ }^{\mathrm{c}}$ & 36.3 & & 29.6 \\
\hline \multicolumn{4}{|l|}{ Usually consult dental personnel when having oral health } \\
\hline symptoms $^{\mathrm{c}}$ & 78.7 & $* *$ & 69.3 \\
\hline \multicolumn{4}{|l|}{ Usually consult dental personnel when having severe oral } \\
\hline health symptoms ${ }^{\mathrm{c}}$ & 69.5 & & 70.1 \\
\hline \multicolumn{4}{|l|}{ Restorative self-care } \\
\hline Checkup oral health once a year ${ }^{c}$ & 86.7 & & 81.6 \\
\hline Have full mouth scaling and polishing once a year ${ }^{\mathrm{a}}$ & 64.1 & & 61.1 \\
\hline Strictly follow dentist's instructions after treatment ${ }^{\mathrm{c}}$ & 87.6 & 82.8 & \\
\hline
\end{tabular}


${ }^{a} n=617$ : participants who had at least one tooth remaining in their

mouth

${ }^{\mathrm{b}} \mathrm{n}=150$ : participants who wear both professional and non-

professional denture types

${ }^{\mathrm{c}} \mathrm{n}=695$ : all participants

${ }^{*} \mathrm{P}<0.05,{ }^{* *} \mathrm{P}<0.01,{ }^{* * *} \mathrm{P}<0.001$ : chi-square test

The oral health outcome in terms of 'having at least four pairs of occlusal teeth' was significantly different between the two participating groups, while indicators of the oral health-related quality of life (OHRQoL) as overall oral health and prevalence of OHRQoL as assessed by the Thai-OHIP were found to be similar (Table 3).

Table 3. Oral health outcomes of elderly people with and without oral health promoting elderly clubs

\begin{tabular}{l|l|l}
\hline \multicolumn{2}{l}{ Percentage of elderly people } & \multicolumn{2}{l}{$\begin{array}{l}\text { with an oral health } \\
\text { promoting elderly } \\
\text { Oral health outcome }\end{array}$} & $\begin{array}{l}\text { without an oral } \\
\text { health promoting } \\
\text { elderly club }\end{array}$ \\
\hline $\begin{array}{l}\text { Oral health status } \\
\text { Have at least twenty teeth remaining in their mouth }\end{array}$ & 61.7 & 54.6 \\
$\begin{array}{l}\text { Having at least four pairs of occlusal teeth } \\
\text { Oral health-related quality of life (OHRQoL) }\end{array}$ & $69.2^{*}$ & 60.6 \\
Overall oral health satisfied & 87.6 & 88.2 \\
$\begin{array}{l}\text { Prevalence of OHRQoL assessed by the Thai-OHIP } \\
\text { * }<<0.05: \text { chi-square test }\end{array}$ & 54.8 & 53.2 \\
\hline
\end{tabular}

\section{Discussion}

The strategy of oral health promotion through elderly clubs has been driven for the past 13 years and coverage is still expanding. Previous studies found positive outcomes of oral health-promoting elderly clubs $[\mathbf{7 , 1 7 ]}$ but a comprehensive evaluation at the country level has never been conducted. The objective of this study was to explore the outcomes of the oral health-promoting elderly clubs in Thailand. A comparison of oral health-related behaviors and oral health outcomes was made between elders from areas with and without oral health promotion clubs.

Nineteen questions that assessed oral health-related behaviors were classified into four categories as 1) Regulatory self-care, 2) Preventive self-care, 3) Reactive self-care, and 4) Restorative selfcare. Six out of 19 behaviors showed a significant relationship with the existence of oral health-promoting elderly clubs. Of these, four behaviors were classified into the regulatory self-care group and included brushing teeth after lunch, brushing teeth at night, using dental floss, and using a proxabrush, while two behaviors were classified into the preventive self-care and reactive self-care groups as never smoked/quit smoking and consulting dental personnel when having oral health symptom, respectively. Superior behavior characteristics were related to the existence of clubs but some findings might be overclaimed by oral health-promoting elderly clubs. This might occur because these outcomes are the objectives of the National Oral Health Plan for Senior Citizens that consists of various strategies [2], while the cross-sectional study design confirmed only the relationship between the variables.

Findings of oral health-related behaviors from this study were better than the latest national oral health survey of Thailand in terms of eating nothing after brushing teeth at night, removing and cleaning dentures after eating, using supplementary oral health care, whether as dental floss, a proxabrush, a toothpick or mouth rinse and oral health self-examination [3]. These improvements might reflect enhanced oral health service delivery that is another strategy in the national plan [2], since better access to care leads to direct communication with oral health practitioners who can then perform personal oral health promotion at the chairside $[9,10]$. By contrast, smoking behavior did not show improved results while this is a common risk factor shared with other non-communicable diseases

[13] (Figure 1). This is a big challenge for personnel responsible for oral health care because the ultimate goal of the system is to promote oral health self-care for elders to maintain good or al health. Therefore, all oral health-related behaviors must be considered, not only cleaning behaviors.

'Having at least twenty teeth with at least four pairs of occlusal teeth' is the expected outcome, however, in this study, the presence of four pairs of occlusal teeth included participants wearing dentures. Therefore, the significant association between this outcome and implementation of oral health-promoting elderly clubs might be 
confounded by access to oral health services.

While no relationship of the OHRQoL was found with the implementation of oral health-promoting elderly clubs, but this issue should not be overlooked. As the FDI's recommendation that the key performance indicators for assessment of oral health care needs and cost-effectiveness, as well as planning oral health services and setting policies, should be included in the OHRQoL together with clinical and behavioral indicators [8]

The main limitation of this study was the cross-sectional design. This constricted the analysis to explore only the relationships between the included variables. Causes and effects as the major objective of the evaluation were not considered. Further research is recommended using these results as baseline data. Another limitation resulted from the process of data collection. Sampling selection for elders who joined activities at the health center excluded males who commonly went to work during the daytime [14]. Thus, the majority of elders in the study were female at a higher proportion than the national statistics average [6]. This situation implied that any activities during

\section{Conflict of interest}

The main author was a staff of the Bureau of Dental Health at the period of this study and has received a research grant from the Department of Health, Ministry of Public Health, Thailand.

Funding: This work was supported by the Department of Health, Ministry of Public Health, Thailand.

\section{References}

1. Barofsky I (1978) Compliance, adherence and the therapeutic alliance: Steps in the development of self-care. Social Science \& Medicine. Part A: Medical Psychology \& Medical Sociology. 12(5A): 369-376.

2. Bureau of Dental Health. (2014) National Oral Health Plan for Senior Citizens, Thailand. In: Department of Health (ed)

3. Bureau of Dental Health. (2018) Report on the Eighth National Oral Health Survey of Thailand (2017). Nonthaburi: Ministry of Public Health.

4. Bureau of Dental Health. (2020) Summary of the oral health promoting elderly club.

5. Chaiphotchanaphong N, Tumrasvin W and Krisdapong S. (2011) Thai version of the Oral Health Impact Profile (Thai-OHIP).

6. Department of Provincial Administration. (2019) Official statistics registration systems.

7. Dumrong T (2013) Oral Health Promotion in Senior Clubs in the Eastern Part of Thailand. Thai Dental Public Health Journal 18(1): 49-63.

8. FDI World Dental Federation. (2015) Oral Health and Quality of Life. FDI General Assembly. the daytime at oral health-promoting elderly clubs were attended mainly by female elders. This led to the third issue of selecting health promotion activities that were compatible with the daily life cycles of males. Men commonly have more oral health issues than women. The lower number of functional teeth among males affects their chewing ability and nutritional status $[\mathbf{1 2 , 1 5 , 1 6 ]}$. Males are more prone to the deleterious effects of smoking cigarettes that adversely impact dental hygiene.

In conclusion, the findings present significant associations between existing oral health-promoting elderly clubs and some oral healthrelated behaviors and oral health outcomes among the elders. Furthermore, three suggestions are proposed for the benefit of Thai oral health system planners: 1) smoking behavior should be addressed as a major deleterious factor for both oral hygiene and physical health,

2) OHRQoL should be included as an indicator to better monitor and evaluate the performance of oral health systems, and 3) a new approach should be adopted for oral health promotion by targeting elderly men.

\section{Acknowledgment}

The authors would like to thank all elders who participated in this study. Special thanks go to the oral health practitioners, who are representatives from Lamphun, Lampang, Nakhon Ratchasima, Mukdahan, Roi Et, Ubon Ratchathani, Umnad Chareun, Suphan Buri, Sa Kaew, Nakhon Si Thammarat, Song Khla, and Surat Thani province, for all of their help.

9. Kay E, Locker D (1998) A systematic review of the effectiveness of health promotion aimed at improving oral health. Community Dent Health 15(3): 132-144.

10. McMillan W (2011) Making the most of teaching at the chairside. European Journal of Dental Education. 15(1): 63-68.

11. Pectcharath K (2013) Statute on the National Health System B.E. 2552 (2009) Towards the well-being of Thai people.

12. Samnieng P, Ueno M, Shinada K, Zaitsu T, Wright FAC, et al. (2011) Oral Health Status and Chewing Ability is Related to Mini-Nutritional Assessment Results in an Older Adult Population in Thailand. Journal of Nutrition in Gerontology and Geriatrics. 30(3): 291-304.

13. Sheiham A, Watt RG (2000) The Common Risk Factor Approach: a rational basis for promoting oral health. Community Dentistry and Oral Epidemiology. 28(6): 399-406.

14. Social Statistics Division. (2018) Summary of key findings in the working situation among Thai elders (2018). Bangkok: National Statistical Office.

15. Srisilapanan P, Malikaew P, Sheiham A (2002) Number of teeth and nutritional status in Thai older people. Community Dent Health. 19(4): 230-236. 
16. Torrungruang K, Tamsailom S, Rojanasomsith K, Sutdhibhisal S, Nisapakultorn K, et al. (2005) Risk Indicators of Periodontal Disease in Older Thai Adults. Journal of Periodontology. 76(4): 558-565.

17. Wasin T (2012) Evaluation of Oral Health Promotion in Elderly
Club in Krabi Province, 2010. Thai Dental Public Health Journal. 17(2): 82-96.

18. World Health Organization. (1986) The Ottawa Charter for Health Promotion. Geneva, Switzerland: World Health Organization. 


\section{QUESTIONNAIRE FOR ASSESS OUTCOMES OF ORAL HEALTH PROMOTING ELDERLY CLUBS}

Part 1: General characteristics

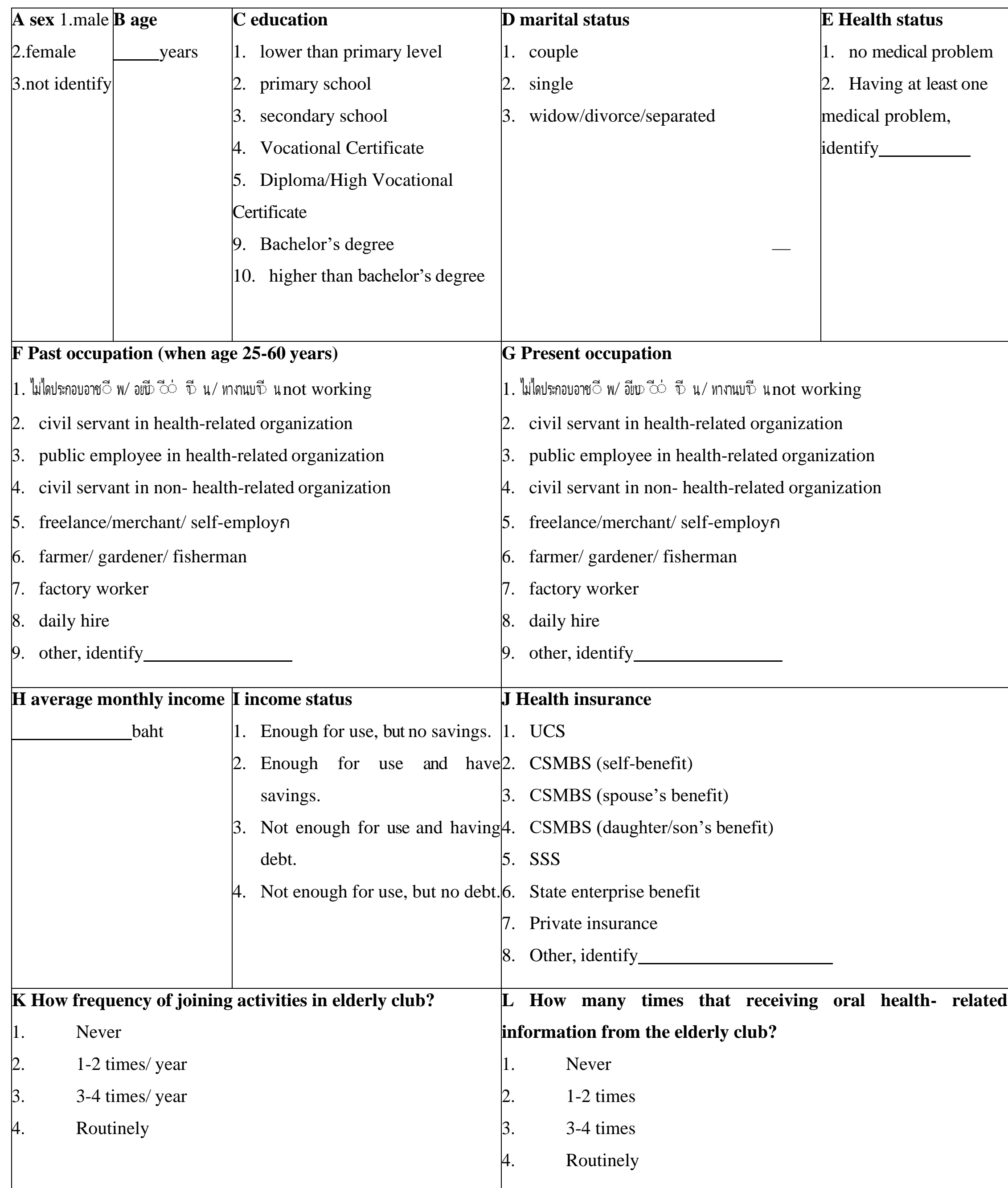

Part 2: Oral health-related behaviors

\begin{tabular}{|l|l|l|l|l|}
\hline Oral health-related behavior in daily life & $\begin{array}{l}\text { Never } \\
\text { (0 day/week) })\end{array}$ & $\begin{array}{l}\text { Sometimes } \\
(1-3 \text { days/week })\end{array}$ & $\begin{array}{l}\text { frequently } \\
\text { (4-6 days/week) }\end{array}$ & $\begin{array}{l}\text { Everyday } \\
\text { (7 days/week) }\end{array}$ \\
\hline $\begin{array}{l}\text { M1 tooth brushing in the morning (if no teeth left, } \\
\text { choose 'never') }\end{array}$ & 1 & 2 & 3 & 4 \\
\hline $\begin{array}{l}\text { M2 tooth brushing after having lunch (if no teeth } \\
\text { left, choose 'never') }\end{array}$ & 1 & 2 & 3 & 4 \\
\hline
\end{tabular}




\begin{tabular}{|l|l|l|l|l|}
\hline $\begin{array}{l}\text { M3 tooth brushing before bed (if no teeth left, } \\
\text { choose 'never') }\end{array}$ & 1 & 2 & 3 & 4 \\
\hline $\begin{array}{l}\text { M4 tooth brushing before bed, then eating again (if } \\
\text { no teeth left, choose 'never') }\end{array}$ & 1 & 2 & 3 & 4 \\
\hline $\begin{array}{l}\text { M5 cleaning denture } \\
\text { (if do not have denture, choose 'never') }\end{array}$ & 1 & 2 & 3 & 4 \\
\hline M6 dental flossing (if no teeth left, choose 'never') & 1 & 2 & 3 & 4 \\
\hline $\begin{array}{l}\text { M7 using proxabrush (if no teeth left, choose } \\
\text { 'never') }\end{array}$ & 1 & 2 & 3 & 4 \\
\hline $\begin{array}{l}\text { M8 using wood stick (if no teeth left, choose } \\
\text { 'never') }\end{array}$ & 1 & 2 & 3 & 4 \\
\hline M9 using mount rinse & 1 & 2 & 3 & 4 \\
\hline M10 oral health self-screening & 1 & 2 & 3 & 4 \\
\hline M11 smoking & 1 & 2 & 3 & 4 \\
\hline M12 chewing betel nut & 1 & 2 & 3 & 4 \\
\hline M13 having sugary snack or drinks & 1 & 2 & 3 & 4 \\
\hline
\end{tabular}

\begin{tabular}{|l|l|l|l|}
\hline Oral health-related behavior & never & sometimes & frequently \\
\hline N1 routinely oral health check up & 1 & 2 & 3 \\
\hline N2 dental scaling/ prophylaxis and apply topical fluoride yearly. & 1 & 2 & 3 \\
\hline N3 Buying over the counter drug for relieving oral health-related pain & 1 & 2 & 3 \\
\hline $\begin{array}{l}\text { N4 Consultation to dental personnel when having some oral health- } \\
\text { related symptom. }\end{array}$ & 1 & 2 & 3 \\
\hline $\begin{array}{l}\text { N5 Consultation to dental personnel when having severe oral health- } \\
\text { related symptom. }\end{array}$ & 1 & 2 & 3 \\
\hline $\begin{array}{l}\text { N6 After treatment, always strictly following dentist's instructions e.g., } \\
\text { gauze biting, drug use }\end{array}$ & 1 & 2 & 3 \\
\hline
\end{tabular}

\begin{tabular}{|l|l|l|l|}
\hline Channel for receiving oral health- related information & never & sometimes & frequently \\
\hline O1 Television & 1 & 2 & 3 \\
\hline O2 Radio & 1 & 2 & 3 \\
\hline O3 Village's radio & 1 & 2 & 3 \\
\hline O4 Poster/ leaflet & 1 & 2 & 3 \\
\hline O5 line group/ Facebook & 1 & 2 & 3 \\
\hline O6 Family & 1 & 2 & 3 \\
\hline O7 Friend & 1 & 2 & 3 \\
\hline O8 Village health volunteer & 1 & 2 & 3 \\
\hline O9 Public health officer & 1 & 2 & 3 \\
\hline O10 Dental personnel & 1 & 2 & 3 \\
\hline O11 Self searching & 1 & 2 & 3 \\
\hline
\end{tabular}

\begin{tabular}{|l|l|l|l|}
\hline Place for receiving oral health- related information & never & sometimes & frequently \\
\hline P1 Home & 1 & 2 & 3 \\
\hline P2 Temple & 1 & 2 & 3 \\
\hline P3 Elderly club & 1 & 2 & 3 \\
\hline P4 Hospital/ Health center/ Clinic & 1 & 2 & 3 \\
\hline P5 other, identify & 1 & 2 & 3 \\
\hline
\end{tabular}


Part 3: Oral health outcomes

\begin{tabular}{|l|}
\hline Q1 Number of upper remaining teeth \\
\hline Q2 Number of lower remaining teeth \\
\hline R1 Upper denture: \\
1. Not have 2. Have removable partial denture 3. Have full denture 4. Have non-professional made denture \\
\hline R2 Lower denture: \\
1. Not have 2. Have removable partial denture 3. Have full denture 4. Have non-professional made denture \\
\hline S Number of occlusal teeth_pairs (both natural teeth and denture) \\
\hline T Overall oral health satisfaction level 1. Not at all/rarely 2. less 3. Moderate 4. very much 5. The most \\
minimal
\end{tabular}

\section{U: The Thai version of the Oral Health Impact Profile (Thai-OHIP)}

\begin{tabular}{|c|c|c|c|c|c|c|}
\hline $\begin{array}{l}\text { numb } \\
\text { er }\end{array}$ & $\begin{array}{l}\text { Do you have problem about teeth mouth or denture in term } \\
\text { of...? }\end{array}$ & never & rarely & sometimes & often & frequently \\
\hline U1 & Have problem in chewing & 0 & 1 & 2 & 3 & 4 \\
\hline $\mathrm{U} 2$ & difficulty saying certain words & 0 & 1 & 2 & 3 & 4 \\
\hline U3 & Notice that some tooth is not normal & 0 & 1 & 2 & 3 & 4 \\
\hline $\mathrm{U} 4$ & feel that your appearance is affected & 0 & 1 & 2 & 3 & 4 \\
\hline U5 & Have bad breath & 0 & 1 & 2 & 3 & 4 \\
\hline U6 & feel that the taste perception of food has deteriorated & 0 & 1 & 2 & 3 & 4 \\
\hline U7 & $\begin{array}{l}\text { Having problems with food particles stuck in your teeth or } \\
\text { dentures }\end{array}$ & 0 & 1 & 2 & 3 & 4 \\
\hline U8 & Feeling that your digestive system is deteriorating & 0 & 1 & 2 & 3 & 4 \\
\hline U9 & Feeling that denture is too loose or too fit & 0 & 1 & 2 & 3 & 4 \\
\hline U10 & Feeling pain inside oral cavity & 0 & 1 & 2 & 3 & 4 \\
\hline U11 & TMJ pain & 0 & 1 & 2 & 3 & 4 \\
\hline $\mathrm{U} 12$ & Headache & 0 & 1 & 2 & 3 & 4 \\
\hline U13 & Tooth sensitive to hot/cold food or drink & 0 & 1 & 2 & 3 & 4 \\
\hline U14 & Toothache & 0 & 1 & 2 & 3 & 4 \\
\hline $\mathrm{U} 15$ & Gum pain & 0 & 1 & 2 & 3 & 4 \\
\hline U16 & Feeling uncomfortable to eat & 0 & 1 & 2 & 3 & 4 \\
\hline U17 & Have sore spot in mouth & 0 & 1 & 2 & 3 & 4 \\
\hline U18 & Had uncomfortable denture & 0 & 1 & 2 & 3 & 4 \\
\hline U19 & Have been worried by dental problem & 0 & 1 & 2 & 3 & 4 \\
\hline $\mathrm{U} 20$ & Worried about your self-image & 0 & 1 & 2 & 3 & 4 \\
\hline $\mathrm{U} 21$ & Dental problems used to make you feel miserable. & 0 & 1 & 2 & 3 & 4 \\
\hline $\mathrm{U} 22$ & Uneasy about the appearance of the teeth oral cavity or denture & 0 & 1 & 2 & 3 & 4 \\
\hline $\mathrm{U} 23$ & Feeling stress & 0 & 1 & 2 & 3 & 4 \\
\hline $\mathrm{U} 24$ & slurred & 0 & 1 & 2 & 3 & 4 \\
\hline $\mathrm{U} 25$ & Someone had misunderstood your words & 0 & 1 & 2 & 3 & 4 \\
\hline U26 & feel that the taste of food has decreased & 0 & 1 & 2 & 3 & 4 \\
\hline $\mathrm{U} 27$ & unable to brush teeth normally & 0 & 1 & 2 & 3 & 4 \\
\hline $\mathrm{U} 28$ & Avoid eating some food & 0 & 1 & 2 & 3 & 4 \\
\hline U29 & feel that your diet is not satisfactory & 0 & 1 & 2 & 3 & 4 \\
\hline $\mathrm{U} 30$ & Unable to eat due to your dentures & 0 & 1 & 2 & 3 & 4 \\
\hline
\end{tabular}




\begin{tabular}{|c|c|c|c|c|c|c|}
\hline U31 & $\begin{array}{l}\text { Avoid smiling because of problem with your teeth, mouth or } \\
\text { dentures }\end{array}$ & 0 & 1 & 2 & 3 & 4 \\
\hline U32 & $\begin{array}{l}\text { stop eating between meals because of problem with your teeth, } \\
\text { mouth or dentures }\end{array}$ & 0 & 1 & 2 & 3 & 4 \\
\hline U33 & $\begin{array}{l}\text { Have sleeping trouble because of problem with your teeth, } \\
\text { mouth or dentures }\end{array}$ & 0 & 1 & 2 & 3 & 4 \\
\hline U34 & $\begin{array}{l}\text { feel offended because of problem with your teeth, mouth or } \\
\text { dentures }\end{array}$ & 0 & 1 & 2 & 3 & 4 \\
\hline U35 & $\begin{array}{l}\text { Cannot feeling relaxed because of problem with your teeth, } \\
\text { mouth or dentures }\end{array}$ & 0 & 1 & 2 & 3 & 4 \\
\hline U36 & $\begin{array}{l}\text { feeling depressed because of problem with your teeth, mouth or } \\
\text { dentures }\end{array}$ & 0 & 1 & 2 & 3 & 4 \\
\hline U37 & สมาธขิ องท่านเคยไดร บผลกรรทบ & 0 & 1 & 2 & 3 & 4 \\
\hline U38 & $\begin{array}{l}\text { Feeling embarrassment because of problem with your teeth, } \\
\text { mouth or dentures }\end{array}$ & 0 & 1 & 2 & 3 & 4 \\
\hline U39 & $\begin{array}{l}\text { avoid going out because of problem with your teeth, mouth or } \\
\text { dentures }\end{array}$ & 0 & 1 & 2 & 3 & 4 \\
\hline U40 & $\begin{array}{l}\text { less tolerant towards spouse or family because of problem with } \\
\text { your teeth, mouth or denture }\end{array}$ & 0 & 1 & 2 & 3 & 4 \\
\hline U41 & $\begin{array}{l}\text { Difficulty getting along with other people because of problem } \\
\text { with your teeth, mouth or denture }\end{array}$ & 0 & 1 & 2 & 3 & 4 \\
\hline U42 & $\begin{array}{l}\text { Have been a bit irritable with other people because of problem } \\
\text { with your teeth, mouth or denture }\end{array}$ & 0 & 1 & 2 & 3 & 4 \\
\hline U43 & $\begin{array}{l}\text { Difficulty doing routine tasks because of problem with your } \\
\text { teeth, mouth or denture }\end{array}$ & 0 & 1 & 2 & 3 & 4 \\
\hline U44 & $\begin{array}{l}\text { feel that your general health has deteriorated because of } \\
\text { problem with your teeth, mouth or denture }\end{array}$ & 0 & 1 & 2 & 3 & 4 \\
\hline U45 & $\begin{array}{l}\text { facing cost problems because of problem with your teeth, } \\
\text { mouth or dentures }\end{array}$ & 0 & 1 & 2 & 3 & 4 \\
\hline U46 & $\begin{array}{l}\text { Have been unable to enjoy other people's company as much } \\
\text { because of problem with your teeth, mouth or dentures }\end{array}$ & 0 & 1 & 2 & 3 & 4 \\
\hline U47 & $\begin{array}{l}\text { feeling less satisfaction in life because of problem with your } \\
\text { teeth, mouth or dentures }\end{array}$ & 0 & 1 & 2 & 3 & 4 \\
\hline U48 & $\begin{array}{l}\text { could not doing anything because of problem with your teeth, } \\
\text { mouth or dentures }\end{array}$ & 0 & 1 & 2 & 3 & 4 \\
\hline U49 & $\begin{array}{l}\text { could not doing full performance because of problem with your } \\
\text { teeth, mouth or dentures }\end{array}$ & 0 & 1 & 2 & 3 & 4 \\
\hline U50 & Cheek biting & 0 & 1 & 2 & 3 & 4 \\
\hline U51 & Dry mouth & 0 & 1 & 2 & 3 & 4 \\
\hline U52 & Clicking when widely mouth opening or chewing & 0 & 1 & 2 & 3 & 4 \\
\hline U53 & $\begin{array}{l}\text { avoid eating with others because of problem with your teeth, } \\
\text { mouth or dentures }\end{array}$ & 0 & 1 & 2 & 3 & 4 \\
\hline U54 & $\begin{array}{l}\text { use longer time for each meal because of problem with your } \\
\text { teeth, mouth or dentures }\end{array}$ & 0 & 1 & 2 & 3 & 4 \\
\hline
\end{tabular}

